\title{
$\beta$-catenin knockdown promotes NHERF1-mediated survival of colorectal cancer cells: implications for a double-targeted therapy
}

\author{
Concetta Saponaro ${ }^{1,2}$ - Sara Sergio ${ }^{1,3} \cdot$ Antonio Coluccia $^{4}$ - Maria De Luca ${ }^{3}$ - Giuseppe La Regina ${ }^{4}$ Luca Mologni $^{5}$. \\ Valeria Famiglini ${ }^{4}$ - Valentina Naccarato ${ }^{4}$. Daniela Bonetti ${ }^{6}$. Candice Gautier ${ }^{6}$ Stefano Gianni ${ }^{6}$. \\ Daniele Vergara $\mathbb{1}^{1,3} \cdot$ Michel Salzet $\mathbb{1}^{7} \cdot$ Isabelle Fournier $\mathbb{1}^{7} \cdot$ Cecilia Bucci $\mathbb{1}^{3} \cdot$ Romano Silvestri ${ }^{4}$. \\ Carlo Gambacorti Passerini ${ }^{5} \cdot$ Michele Maffia $^{1,3} \cdot$ Addolorata Maria Luce Coluccia $^{1,3}$
}

Received: 18 September 2017 / Revised: 13 December 2017 / Accepted: 22 January 2018 / Published online: 19 March 2018

(c) The Author(s) 2018. This article is published with open access

\begin{abstract}
Nuclear activated $\beta$-catenin plays a causative role in colorectal cancers (CRC) but remains an elusive therapeutic target. Using human CRC cells harboring different $\mathrm{Wnt} / \beta$-catenin pathway mutations in APC/KRAS or $\beta$-catenin/KRAS genes, and both genetic and pharmacological knockdown approaches, we show that oncogenic $\beta$-catenin signaling negatively regulates the expression of NHERF1 $\left(\mathrm{Na}^{+} / \mathrm{H}^{+}\right.$exchanger 3 regulating factor 1), a PDZ-adaptor protein that is usually lost or downregulated in early dysplastic adenomas to exacerbate nuclear $\beta$-catenin activity. Chromatin immunoprecipitation (ChIP) assays demonstrated that $\beta$-catenin represses NHERF1 via TCF4 directly, while the association between TCF1 and the Nherfl promoter increased upon $\beta$-catenin knockdown. To note, the occurrence of a cytostatic survival response in settings of single $\beta$-catenin-depleted CRC cells was abrogated by combining NHERF1 inhibition via small hairpin RNA (shRNA) or RS5517, a novel PDZ1-domain ligand of NHERF1 that prevented its ectopic nuclear entry. Mechanistically, dual NHERF1/ $\beta$-catenin targeting promoted an autophagy-to-apoptosis switch consistent with the activation of Caspase-3, the cleavage of PARP and reduced levels of phospho-ERK1/2, Beclin-1, and Rab7 autophagic proteins compared with $\beta$-catenin knockdown alone. Collectively, our data unveil novel $\beta$-catenin/TCF-dependent mechanisms of CRC carcinogenesis, also offering preclinical proof of concept for combining $\beta$-catenin and NHERF1 pharmacological inhibitors as a mechanism-based strategy to augment apoptotic death of CRC cells refractory to current $\mathrm{Wnt} / \beta$-catenin-targeted therapeutics.
\end{abstract}

Electronic supplementary material The online version of this article (https://doi.org/10.1038/s41388-018-0170-y) contains supplementary material, which is available to authorized users.

Addolorata Maria Luce Coluccia

malu.coluccia@unisalento.it

michele.maffia@unisalento.it

1 Laboratory of Clinical Proteomics, Giovanni Paolo II Oncology Hospital, I-73100 Lecce, Italy

2 Functional Biomorphology Laboratory, IRCCS Istituto Tumori "Giovanni Paolo II", Bari, Italy

3 Department of Biological and Environmental Sciences and Technologies, University of Salento, I-73100 Lecce, Italy

4 Department of Drug Chemistry and Technologies, Sapienza

\section{Introduction}

Nuclear activated $\beta$-catenin caused by Wnt-pathway mutations is the earliest driving event in hereditary (10\%) and sporadic (90\%) human colorectal cancers (CRC) [1]. Deletion of the tumor suppressor adenomatous polyposis coli $(A P C)(>80 \%)$ or 'gain-of-function' mutations in GSK3 $\beta$-target residues in $\beta$-catenin gene (5-10\%) increase

University of Rome, Laboratory affiliated to Istituto Pasteur Italia - Fondazione Cenci Bolognetti, Piazzale Aldo Moro 5, I-00185 Roma, Italy

5 Department of Clinical Medicine, San Gerardo Hospital, University of Milano-Bicocca, I-20052 Monza, Italy

6 Department of Biochemistry, Sapienza University of Rome, Laboratory affiliated to Istituto Pasteur Italia - Fondazione Cenci Bolognetti, Piazzale Aldo Moro 5, I-00185 Roma, Italy

7 U1192-Laboratoire Protéomique, Réponse Inflammatoire et Spectrométrie de Masse (PRISM), F-59000 Lille, France 
A

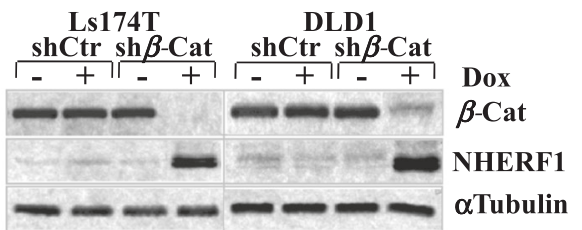

B

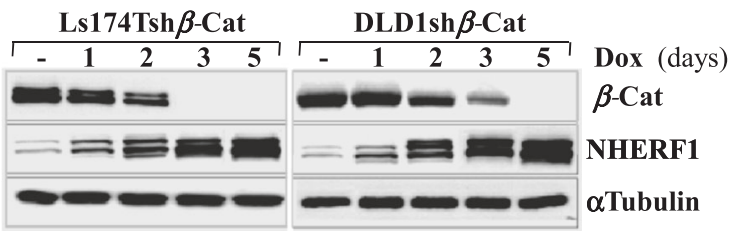

C
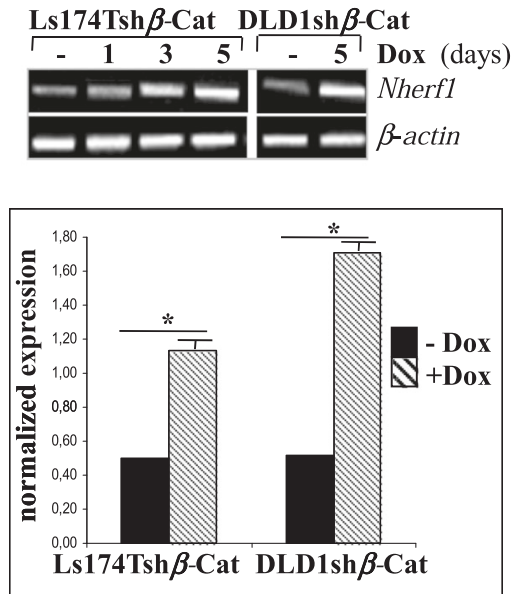

D

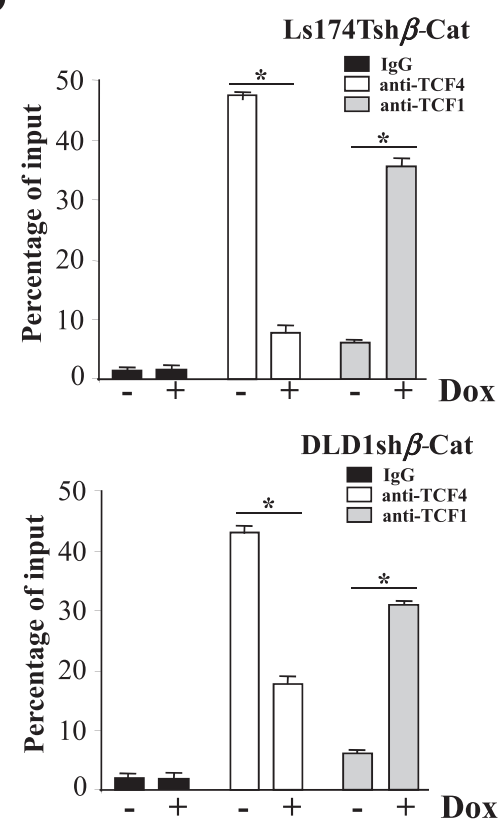

Dox at the indicated time points, was analyzed by RT-PCR for assessing nherfl and $\beta$-actin mRNA levels. The normalized nher$f l$ expression versus $\beta$-actin mRNA at day 5 was quantified by using Image $\mathrm{J}$ analysis software for Windows. Data from three independent experiments were presented as means \pm SEM $\left({ }^{*} p<0.05\right)$. d ChIP of TCF1 and TCF4 in the Nherf1 promoter region in Ls174Tsh $\beta$-Cat and DLD1 $\operatorname{sh} \beta$-Cat cells cultured in the absence $(-)$ or presence of Dox $(+)$ for 5 days. qPCR was performed to quantify ChIP assay results. Enrichment was quantified relative to input controls. An anti-IgG antibody was used as a negative control. Results are represented as the average \pm SD of three independent experiments $\left({ }^{*} p<0.01\right)$

Despite its causative role in $\mathrm{CRC}$, however, $\beta$-catenin remains an elusive therapeutic target. Targeting of $\beta$-catenin by small hairpin RNAs (shRNAs) or pharmacological inhibitors reduces the growth of established CRC xenografts in vivo without affecting the viability of malignant cells $[3,4]$. CRC cells harboring inducible $\beta$-catenin shRNAs undergo cell cycle arrest, differentiate into polarized epithelial cells but rapidly resume their proliferative 

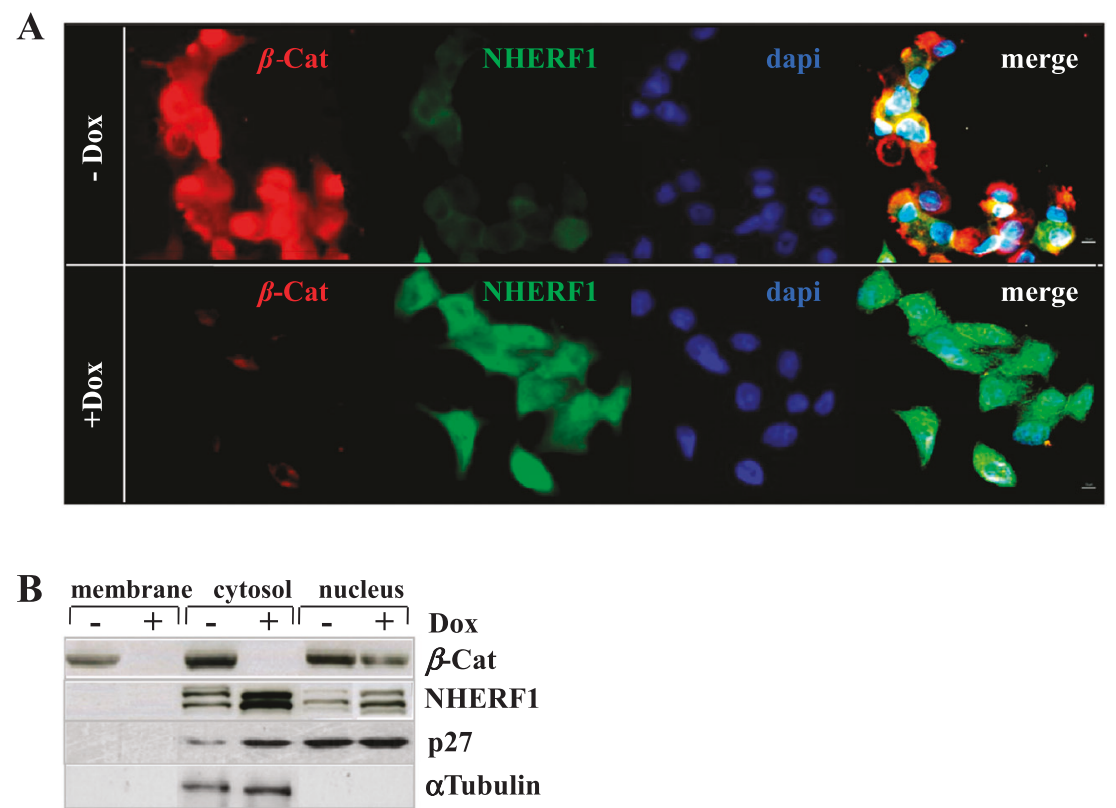

Fig. 2 Ectopic cytoplasmic and nuclear overexpression of NHERF1 in $\beta$-catenin-depleted CRC adenocarcinoma cells. a Ls174Tsh $\beta$-Cat were cultured in the absence or presence of Dox (-Dox/+Dox) for 5 days, stained with primary antibodies for $\beta$-catenin $(\beta$-Cat) or NHERF1 and visualized with a fluorescent IgG-TRITC (for $\beta$-Cat) or IgG-FITC (for NHERF1) secondary antibodies by laser scanning confocal microscopy. DNA was stained with 4',6-diamidino-2-phenylindole (DAPI). A merge of the two fluorescence signals and DAPI staining is also

potential when relieved from $\beta$-catenin inhibition in vitro [5, 6]. Thus, from a biological and therapeutic perspective, a better characterization of the signaling outcome of $\beta$-catenin knockdown could provide new molecular events tied to survival control in CRC tumorigenesis that could be potentially used in combination therapy to improve the efficacy of Wnt-targeted approaches at early disease stages.

NHERF1 $\left(\mathrm{Na}^{+} / \mathrm{H}^{+}\right.$exchanger 3 regulating factor 1$)$ is a membrane adaptor protein that contains two tandem PDZ (post-synaptic density 95/discs large/zona occludens 1) domains and physiologically recruits $\beta$-catenin underneath the plasma membrane to shape proper tissue morphogenesis and homeostasis [7]. Recent data earmark NHERF1 as a tumor suppressor upstream of $\mathrm{Wnt} / \beta$-catenin-driven intestinal tumorigenesis in vivo [8]. The complete lack of NHERF1 expression, either by shRNA knockdown in CRC cells or by gene knockout $\left(\mathrm{NHERF1}^{-/-}\right)$in $\mathrm{Apc}^{\mathrm{Min} /+}$ mutant mice that develop multiple intestinal adenomas, was reported to increase tumor growth and the transactivating effects of $\beta$-catenin [8]. These data have relatively explained the heterogeneous pattern of NHERF1 observed in primary CRC [9-11], where membranous expression of NHERF1 is usually lost in dysplastic adenomas, and either absent or low/ectopically re-expressed thorough the cytoplasm and shown (Magnification, $\times 60$ ). Each confocal image is representative of three independent experiments. b DLD $1 \operatorname{sh} \beta$-Cat cells were cultured in the absence or presence of $2 \mu \mathrm{g} / \mathrm{mL}$ of Dox ( - Dox/+Dox) for 5 days and then fractionated to obtain purified extracts from either membrane, cytosol, and nucleus of cells, as described in Methods section. Equal amounts of each cell extract $(100 \mu \mathrm{g})$ were separated by SDS-PAGE and probed with the indicated antibodies

nuclei in approximately half of differentiated adenocarcinomas [12, 13].

Little is known about molecular mechanisms governing the early loss-of-NHERF1 expression in CRC and, in particular, the impact of oncogenic $\beta$-catenin remains unexploited. Using CRC cells harboring different $\mathrm{Wnt} / \beta$ catenin pathway mutations and low-NHERF1-levels at baseline, we show that genetic or pharmacological knockdown of $\beta$-catenin is sufficient to increase NHERF1 as a major driver of a cytoprotective autophagic response. This prompted us to investigate a double $\beta$-catenin/ NHERF1-inhibitory strategy as a fruitful approach to augment apoptotic death of CRC cells refractory to Wnttargeted agents, indicating RS5517 as a novel NHERF1/ PDZ1-domain ligand antagonist with a promising therapeutic value.

\section{Results}

\section{$\beta$-catenin represses NHERF1 expression by associating with TCF4}

Mechanisms underlying the early lack of NHERF1 in CRC tumorigenesis remain unclear [7]. To determine the impact 
A

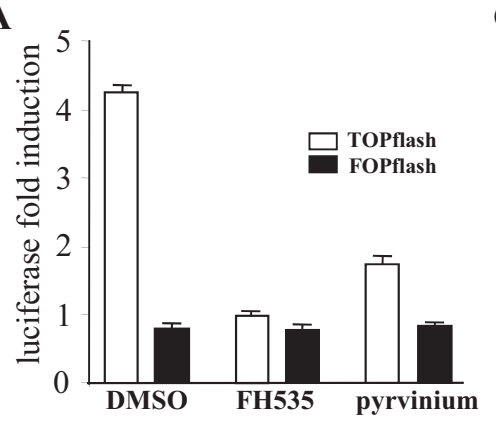

B

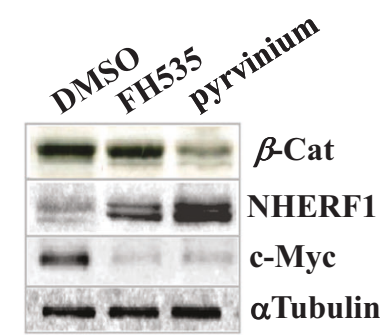

$\mathrm{C}$

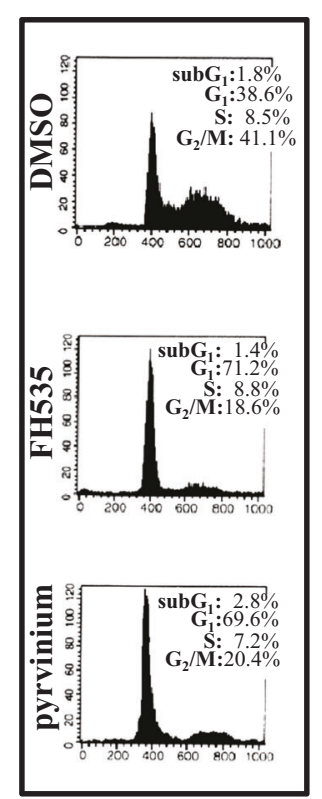

D

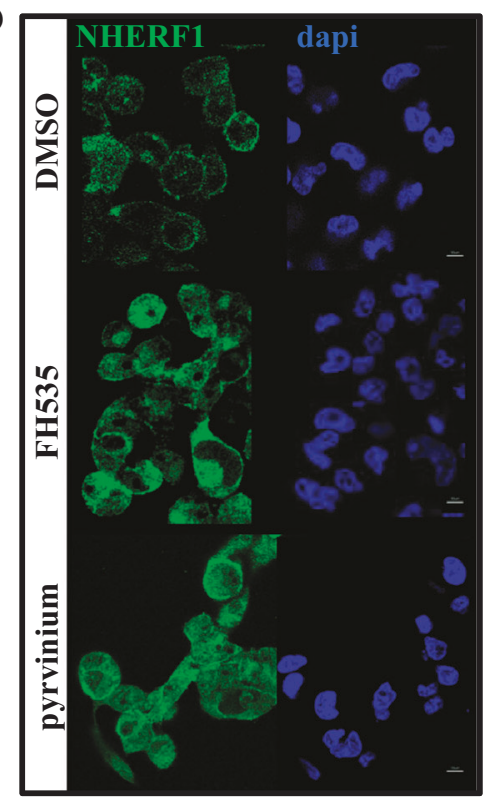

Fig. 3 Small molecule inhibitors of $\beta$-catenin promote NHERF1 overexpression and mislocalization in CRC cells. a Subconfluent Ls174Tsh $\beta$-Cat were co-transfected with the luciferase reporter constructs TOPflash or FOPflash as reported in Methods section. At $24 \mathrm{~h}$ after transfection, cells were treated with vehicle alone (DMSO), FH535 $(1 \mu \mathrm{M})$ or pyrvinium pamoate $(150 \mathrm{nM})$ for additional $72 \mathrm{~h}$. Luciferase activity was expressed as fold activation compared with carrier control cells. Values represent means $\pm S D$ of three representative experiments. b After 4 days of treatment with DMSO, FH535 $(1 \mu \mathrm{M})$ or pyrvinium pamoate $(150 \mathrm{nM})$, total cell lysates were probed for $\beta$-catenin ( $\beta$-Cat), c-Myc and NHERF1 expression. Tubulin served

of $\beta$-catenin on NHERF1 expression, we used an integrated doxycycline (Dox)-inducible shRNA vector to silence $\beta$ catenin in two human cell lines that recapitulate the earliest events implicated in CRC (Ls174T have mutated $\beta$-catenin/ $K R A S$ genes and DLD-1 have mutated APC/KRAS genes) [14-16].

$\beta$-catenin was successfully silenced in $\operatorname{sh} \beta$-catenin stably transfected Ls174T and DLD-1 cells (below named Ls174Tsh $\beta$-Cat and DLD1sh $\beta$-Cat) cultured with Dox $(+$ Dox $)$ compared with untreated cells ( - Dox) or a mock clone expressing a negative control shRNA (shCtr) (Fig. 1a, b). Both CRC cell lines expressed low-steady-state levels of NHERF1 (Fig. 1b, c), while its mRNA transcript and protein levels was gradually increased in $\operatorname{sh} \beta$-Cat-depleted CRC cells maintained under Dox ( + Dox), achieving a peak of induction upon complete $\beta$-catenin knockdown (Fig. 1b, c). Then we performed ChIP assays to determine whether $\beta$ catenin regulates NHERF1 via recruiting key transcriptional mediators of the Wnt pathway like TCF1, also called transcription factor 7 (TCF7), and TCF4 also called transcription factor 7-like 2 (TCF7L2), both of which involved in CRC carcinogenesis [1,2]. We observed that knockdown of $\beta$-catenin strikingly reduced the binding of TCF4 with the as a loading control. c Ls174Tsh $\beta$-Cat cells exposed for 4 days to DMSO, FH535 $(1 \mu \mathrm{M})$ or pyrvinium pamoate $(150 \mathrm{nM})$ were analyzed by propidium iodide-staining and flow cytometric analysis for assaying cell cycle distribution, as described in Methods section. A representative dot plot of three replicate experiments shows the percentages of cells into different phases of the cell cycle for each indicated treatment. d Each confocal image is representative of three indipendent immunofluorescence analyses of NHERF1 by a rabbit polyclonal antibody visualized with a fluorescent IgG-FITC secondary antibody for the indicated treatments (left panels). DAPI staining (right panels) is also shown (Magnification, $\times 60$ )

Nherf1 promoter, while promoting the association with TCF1 in both CRC cell lines (Fig. 1d).

We also examined the intracellular distribution of NHERF1 and $\beta$-catenin in Ls174Tsh $\beta$-Cat cells by laser scanning confocal microscopy (Fig. 2a). $\beta$-catenin was nearly undetectable in Dox-treated cells correlating with a more pronounced ectopic staining of NHERF1 compared with the Dox-untreated control samples (Fig. 2a). Similar results were obtained by testing DLD $1 \operatorname{sh} \beta$-Cat cells (data not shown), which were also subjected to cell fractionation experiments to assess changes on NHERF1 subcellular compartmentalization during $\beta$-catenin knockdown (Fig. $2 \mathrm{~b})$. A fraction of cortical $\beta$-catenin was evident in Doxuntreated CRC cells ( - Dox), although it was predominantly accumulated in the cytosolic and nuclear fractions, in line with an oncogenic $\beta$-catenin/TCF-transcriptional activation. Following Dox-exposure ( + Dox), $\beta$-catenin remained evident only in the nuclear extracts with ensuing increased cytoplasmic/nuclear NHERF1 levels vs Dox-untreated (-Dox) cells.

We also observed that NHERF1 was significantly upregulated in Ls174Tsh $\beta$-Cat cells treated with FH535 and pyrvinium pamoate, two unrelated drugs that have been 

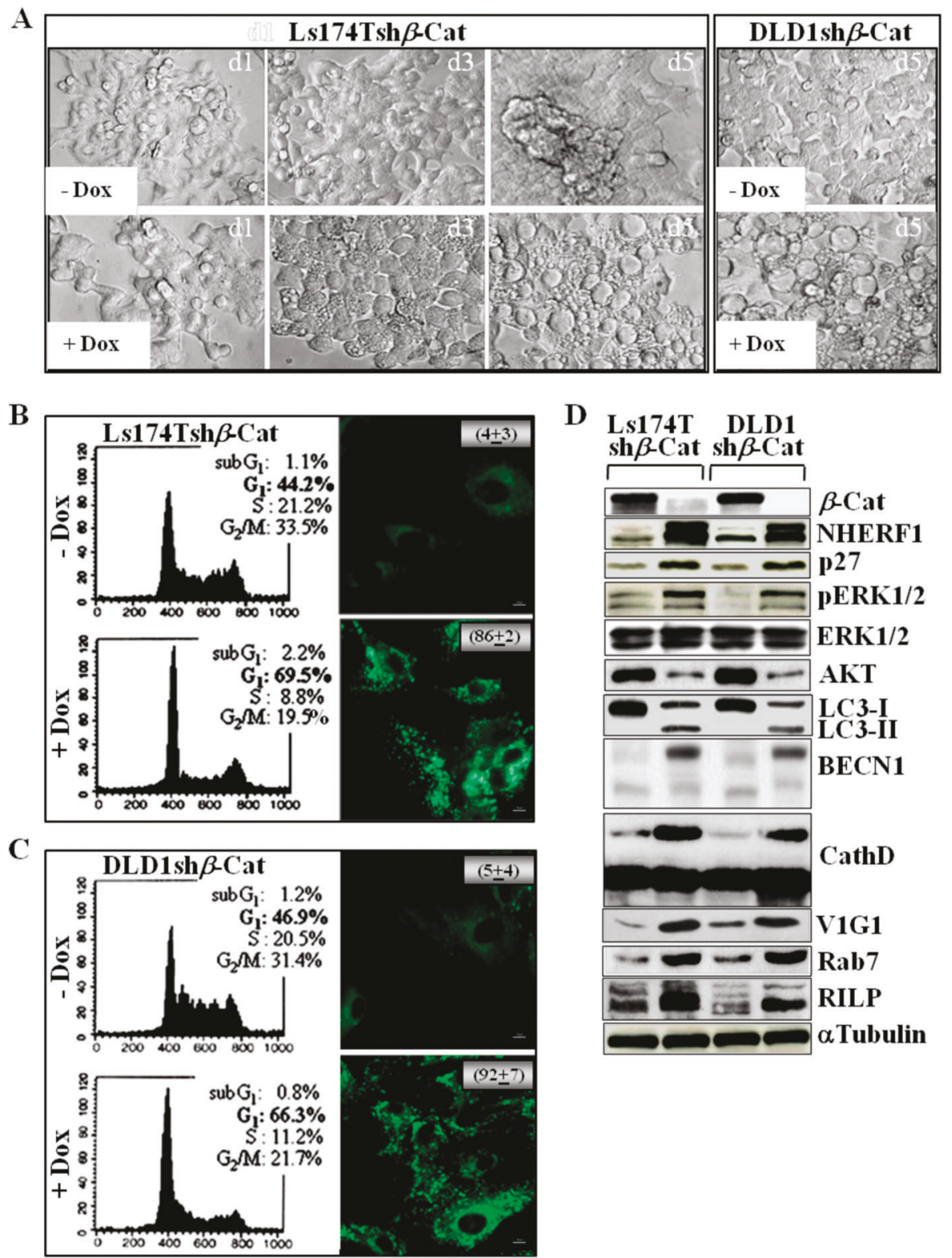

Fig. $4 \beta$-catenin-silenced CRC cells show a unique protein profile centred around autophagy and energy metabolism. Ls174T and DLD1 cells expressing a doxycycline (Dox)-inducible shRNA for $\beta$ catenin (Ls174Tsh $\beta$-Cat and DLD1sh $\beta$-Cat) were cultured without or with $2 \mu \mathrm{g} / \mathrm{mL}$ of Dox (-Dox/+Dox) for 1,3 , or 5 days. a A representative image of cells from one of the six fields captured from each well by using a camera attached to an inverted Olympus IX51 microscope is shown. b After 5 days of treatment without or with doxycycline ( - Dox/+Dox), Ls174Tsh $\beta$-Cat cells were analyzed by propidium iodide-staining and flow cytometric analysis for assaying cell cycle distribution, as described in Methods section. A representative dot plot of three replicate experiments shows the percentages of cells into different phases of the cell cycle for each indicated treatment (left panels). Under the same experimental conditions, Ls174Tsh $\beta$-Cat cells were analyzed for the presence of MDC-positive autophagosomes, distinct dot-like structures trapped in acidic, membrane-rich organelles distributed in the cytoplasm or localizing in the perinuclear regions of CRC cells (Magnification, $\times 60$ ). The numbers indicate the percentage of autophagy induction for each treatment condition. c After 5 days of treatment without or with doxycycline (-Dox/+Dox), cell cycle distribution of DLD1sh $\beta$-Cat cells was analyzed by propidium iodide-staining and flow cytometric analysis. A representative plot of three replicate experiments shows the percentages of cells into different phases of the cell cycle for each indicated treatment (left panels). DLD1sh $\beta$-Cat cells were analyzed for the presence of MDC-positive autophagosomes, as previously reported for Ls174Tsh $\beta$-Cat cells (Magnification, $\times 60$ ). The numbers indicate the percentage of autophagy induction for each treatment condition. d Total cell lysates from Ls174Tsh $\beta$-Cat and DLD1sh $\beta$-Cat cultured without $(-)$ or with $(+)$ Dox for 5 days were assessed by western blotting with the indicated antibodies 
reported to block $\beta$-catenin signaling via different mechanisms (Fig. 3). FH535 is a sulfonamide-based compound that suppresses $\beta$-catenin/TCF-mediated transcription without affecting $\beta$-catenin levels [17]. Pyrvinium is an anthelmintic drug that promotes $\beta$-catenin degradation via activation of $\mathrm{CK} 1 \alpha$ (casein kinase1 $\alpha$ ) [18]. Both drugs reduced transcription from the $\beta$-catenin/TCF-responsive reporter plasmid TOPflash (Fig. 3a) and expression of cMyc, a $\beta$-catenin transcriptional target that promotes cell proliferation (Fig. 3b). The two drugs induced CRC cell cycle arrest without significant apoptosis (Fig. 3c) [5, 6] and increased low-endogenous NHERF1 levels, as well as its ectopic cytoplasmic/nuclear subcellular distribution, although at a higher extent in pyrvinium vs FH535-treated cells (Fig. 3b, d).

To our knowledge, these data unveils a new oncogenic role for $\beta$-catenin in CRC through very early NHERF1 suppression at the transcriptional level via TCF4 directly.

\section{Genetic targeting of $\beta$-catenin and NHERF1 causes massive CRC apoptosis}

Knockdown of $\beta$-catenin promoted cell differentiation coupled to a prominent vacuolization in Dox-treated (+Dox) Ls174Tsh $\beta$-Cat and DLD- $1 \operatorname{sh} \beta$-Cat cells vs their untreated counterparts (-Dox) (Fig. 4a) [5, 6]. These changes were reversible on Dox removal (data not shown). Similarly to pharmacological targeting of $\beta$-catenin (Fig. 3), genetic depletion of $\beta$-catenin was sufficient to cause cell cycle arrest (Fig. 4b, c, left panels) sustaining an adaptive autophagic response, as judged by staining for monodansylcadaverine (MDC) used as a hallmark of autophagic vacuoles (Fig. 4b, c, right panels). As shown in Fig. 4d, heightened endogenous levels of NHERF1 in settings of viable $\beta$-catenin-depleted CRC cells also correlated with hyper-phosphorylated ERK1/2 (pERK1/2) and increased levels of the cell cycle inhibitor p27, as well as of key endocytosis/autophagy regulators, such as the microtubuleassociated protein light chain 3 (LC3), Beclin-1 (BECN1), Cathepsin D, the regulatory V1G1 subunit of the vacuolar ATPase (V-ATPase), the small GTPase Rab7 and its effector RILP [19, 20]. Specifically, the accumulation of LC3-II, Beclin-1, and Cathepsin D isoforms were specific molecular makers of autophagy predicted based on morphological parameters (Fig. 4a). These findings were corroborated by an unbiased broad proteomic characterization indicating that 1161 proteins were differentially expressed in Ls174T $\operatorname{sh} \beta$-Cat cells cultured with or without doxycycline $( \pm$ Dox $)$ (Supplementary Figure S1). The heat-map generated by Perseus segregated samples into two separated branches characterized respectively by 464 proteins upregulated (Cluster 1) and 697 proteins downregulated (Cluster
2 ) in $\beta$-catenin-depleted cells. Each protein cluster was also enriched with specific signaling cascades based on KEGG (Kyoto Encyclopedia of Genes and Genomes) pathway analysis using STRING software (Table 1). These proteins were statistically categorized by STRING (false discovery rate $\leq 1.31 \mathrm{e}-05$ ) showing that Cluster 1 was enriched with proteins involved in the assembling of actin cytoskeleton and adherens junctions, fatty acid degradation, phagosome/ lysosome maturation, autophagy, and endocytosis. Conversely, downregulated proteins into the Cluster 2 were involved in the regulation of spliceosome, RNA transport and ribosome biogenesis. This proteomic profiling corroborated the molecular changes reported in Fig. 4d, earmarking differences into our dataset in terms of energy metabolism, actin filament-based processes and especially autophagic/endocytic processes.

Overall these considerations prompted us to investigate whether NHERF1 could play a role in modulating ERK1/2 and Rab7 expression upon $\beta$-catenin depletion (Fig. 5). To this end, Ls174Tsh $\beta$-Cat or DLD1 $\operatorname{sh} \beta$-Cat cells were transiently transfected with NHERF1 targeted shRNAs (shNHERF1) or scramble shRNAs as control (shCtr) and then cultured with or without Dox $( \pm$ Dox $)$ to modulate concomitantly stable si $\beta$-catenin expression. As shown in Fig. 5a, NHERF1 knockdown alone did not alter overall phospho-ERK1/2, Beclin-1 (BECN1), Rab7, and PARP protein levels at baseline, while combined targeting of NHERF1 and $\beta$-catenin annulled the hyper-activation of ERK1/2 and the accumulation of the autophagy markers Beclin-1 (BECN1) and Rab7 elicited by single- $\beta$-catenin depletion (Fig. 5a, 4d). Such molecular changes were consistent with a massive apoptotic death occurrence in Doxtreated Ls174Tsh $\beta$-Cat/shNHERF1 $(75 \pm 6 \%)$ and DLD1sh $\beta$-Cat/shNHERF1 $(82 \pm 8 \%)$ cells, compared with $<5 \%$ in controls ( $\mathrm{sh} \beta$-Cat/siCtr+Dox or $\operatorname{sh} \beta$-Cat/ shNHERF1-Dox) (Fig. 5b, c), as further confirmed by the cleavage of PARP (Fig. 5a) and Caspase-3 activity (Fig. 5d). Interestingly, we also noticed a modest increase of $\beta$ catenin protein amounts in $\operatorname{sh} \beta$-Cat/shNHERF1 maintained with or without Dox for 4 days (Fig. 5a), in keeping with additive affects that NHERF1 knockdown extents on $\beta$ catenin stabilization reported by others [8]. Moreover, NHERF1 knockdown alone conferred a moderate clonogenic advantage to Dox-untreated Ls174Tsh $\beta$-Cat or DLD1sh $\beta$-Cat cells (Supplementary Figures S2A and S2B) which showed a more sprouted/invasive phenotype when cultured in sub-confluent monolayers (Fig. 5b) or in soft agar (Supplementary Figure S2C).

Collectively, these data indicate that combining NHERF1 inhibition in settings of $\beta$-catenin-silenced CRC cells, in which NHERF1 is highly/ectopically re-expressed, is mandatory to promote an autophagy-to-apoptosis switch in CRC cells refractory to single- $\beta$-catenin targeting. 
Table 1 The principle KEGG pathways of the upregulated and downregulated genes

\begin{tabular}{|c|c|c|c|c|c|}
\hline & Category & Pathway ID & Pathway description & Count in gene set & False discovery rate \\
\hline \multirow[t]{11}{*}{ Upregulated } & KEGG_PATHWAY & 01100 & Metabolic pathways & 80 & $4.79 \mathrm{e}-17$ \\
\hline & KEGG_PATHWAY & 04810 & Regulation of actin cytoskeleton & 24 & $8.5 \mathrm{e}-09$ \\
\hline & KEGG_PATHWAY & 05132 & Salmonella infection & 15 & $3.03 \mathrm{e}-08$ \\
\hline & KEGG_PATHWAY & 04145 & Phagosome & 19 & $3.45 \mathrm{e}-08$ \\
\hline & KEGG_PATHWAY & 04721 & Synaptic vesicle cycle & 13 & $3.6 e-08$ \\
\hline & KEGG_PATHWAY & 05110 & Vibrio cholerae infection & 12 & $4.97 \mathrm{e}-08$ \\
\hline & KEGG_PATHWAY & 04142 & Lysosome & 17 & $6.65 e-08$ \\
\hline & KEGG_PATHWAY & 04144 & Endocytosis & 20 & $5.05 \mathrm{e}-07$ \\
\hline & KEGG_PATHWAY & 05130 & Pathogenic Escherichia coli infection & 11 & $5.54 \mathrm{e}-07$ \\
\hline & KEGG_PATHWAY & 00071 & Fatty acid degradation & 10 & $7.72 \mathrm{e}-07$ \\
\hline & KEGG_PATHWAY & 04530 & Tight junction & 17 & $7.72 \mathrm{e}-07$ \\
\hline \multirow[t]{5}{*}{ Downregulated } & KEGG_PATHWAY & 03040 & Spliceosome & 50 & $1.71 \mathrm{e}-38$ \\
\hline & KEGG_PATHWAY & 03013 & RNA transport & 40 & $1.06 \mathrm{e}-22$ \\
\hline & KEGG_PATHWAY & 03008 & Ribosome biogenesis in eukaryotes & 27 & $1.68 \mathrm{e}-19$ \\
\hline & KEGG_PATHWAY & 03010 & Ribosome & 34 & $1.68 \mathrm{e}-19$ \\
\hline & KEGG_PATHWAY & 01100 & Metabolic pathways & 96 & $1.2 \mathrm{e}-14$ \\
\hline
\end{tabular}

A high confidence (0.700) was set as the threshold to define significant differences

\section{A novel NHERF1/PDZ1-domain antagonist prevents its nuclear import and synergizes with $\beta$-catenin inhibitors in promoting CRC apoptosis}

Previous studies focused on small molecule ligands of the PDZ1-domain of NHERF1 to prevent its ectopic cytoplasmic/nuclear mislocalization and oncogenic function [21-23]. These studies predicted the canonical inactivating binding motif for the NHERF1 PDZ1-domain on four D/E(S/T)-X-(L/V/I/M) residues that are commonly contained at the C-terminal of its specific ligands, such as DSLL for the $\beta 2$-adrenergic receptor ( $\beta 2-\mathrm{AR})$ or ETWM for the parathyroid hormone receptor (PTHR) [24]. Based on these premises, we herein evaluated the conformational flexibility of NHERF1 PDZ1-DSLL and PDZ1-ETWM peptide complexes by molecular dynamics (MD) simulations to draw a consensus pharmacophore model, as described in Materials and Methods [25, 26]. An in-house library of 6000 compounds was screened using the pharmacophore model leading to the selection of RS5517 as the only one of six lowest-energy derivatives with remarkable cytotoxicity in vitro (Fig. 6 and data not shown).

The chemical structure of RS5517, namely 3-benzyl-5chloro-N-(4-(hydroxymethyl)phenyl)-1H-indole-2-carboxamide, is depicted in Fig. 6a. The analysis of the binding mode of RS5517 led us to identify a series of residues involved in the interactions at the NHERF1 PDZ1 domain (Fig. 6b). Specifically: (i) a key Pi-cation interaction between the R80 guanidine and the benzyl group at position 3 of the indole of RS5517; (ii) hydrophobic contacts between the 2-(4-hydroxymethyl)benzoyl moiety and F27 and I79 of the PDZ1, and between the indole nucleus and V76; (iii) two H-bonds with L27 backbone.

To address the inhibitory effect of RS5517, we resorted to test the effect of this molecule on NHERF1/PDZ1 domain in vitro. A construct encoding for NHERF1 PDZ1 was expressed and challenged with a dansylated peptide corresponding to the $\mathrm{C}$-terminal sequence of $\beta 2$-AR (DNDSLL). In order to measure binding, a fluorescent pseudowild type was produced by replacing Tyr38 of PDZ1 with a Trp. Binding was then measured by Forster Resonance energy transfer between the fluorescent donor (Trp) and acceptor (Dansyl). Binding experiments were performed in the presence and in the absence of a constant concentration of RS5517 (Fig. 6c). It is evident, that, while the PDZ1 is capable to bind the C-terminal sequence of $\beta 2-\mathrm{AR}$ with an affinity of about $10 \mu \mathrm{M}$, binding is essentially abolished in the presence of RS5517. This finding confirms that RS5517 is a specific inhibitor of NHERF1/PDZ1 domain.

To evaluate the growth inhibitory effects of RS5517, Ls174Tsh $\beta$-Cat, or DLD1sh $\beta$-Cat cells were exposed to escalating doses $(0.1-100 \mu \mathrm{M})$ of the compound in the presence or absence of Dox for 4 days and then analyzed by MTT assays. As shown in Fig. 7a, the half maximal inhibitory concentration $\left(\mathrm{IC}_{50}\right)$ for $\mathrm{RS} 5517$ in Dox-untreated Ls174Tsh $\beta$-Cat or DLD1sh $\beta$-Cat cells expressing low levels of NHERF1 was $52 \pm 6 \mu \mathrm{M}$ and $65 \pm 11 \mu \mathrm{M}$, respectively. Conversely, the equivalent $\mathrm{IC}_{50}$ value of RS5517 was reduced to $8 \pm 2 \mu \mathrm{M}$ in Ls174Tsh $\beta$-Cat cells and $11 \pm 5 \mu \mathrm{M}$ in DLD1sh $\beta$-Cat cells maintained under concomitant Dox exposure. Our mechanistic investigations suggest that the enhanced cytotoxic effects of RS5517 
A

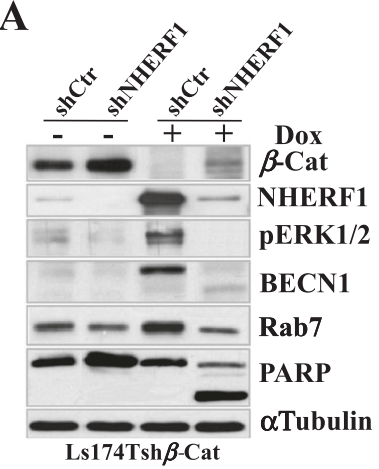

C

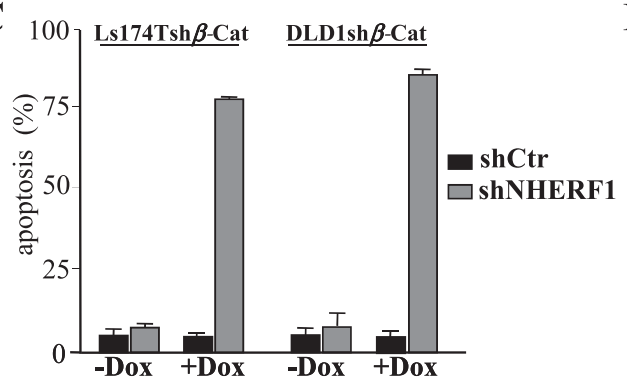

B

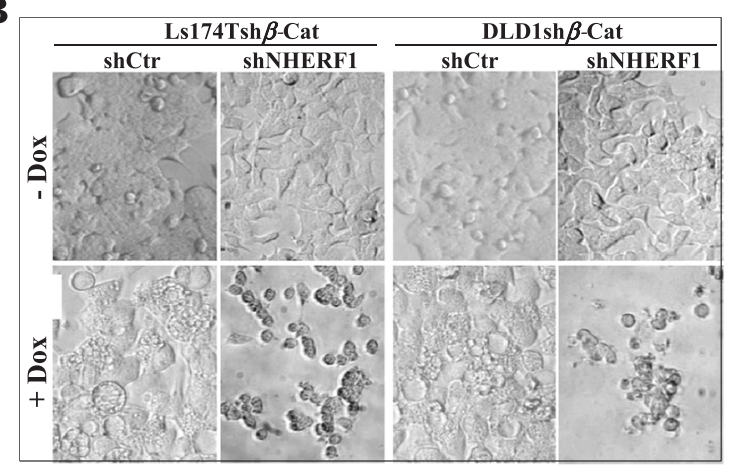

D

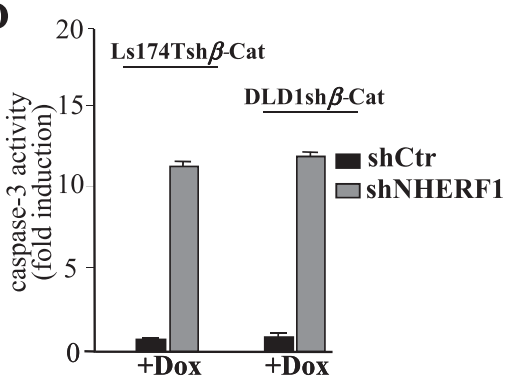

Fig. 5 Combined shRNA-mediated downregulation of $\beta$-catenin and NHERF1-induces apoptosis in human CRC cells. Subconfluent Ls174T cells stably harboring a doxycycline (Dox)-inducible shRNA for $\beta$-catenin (Ls174Tsh $\beta$-Cat) were further transiently transfected with $200 \mathrm{nM}$ of NHERF1 targeted shRNAs (shNHERF1) or scramble shRNAs as control (shCTR). a Total protein extracts from double $\operatorname{sh} \beta$ Cat/shCTR or $\operatorname{sh} \beta$-Cat/shNHERF1 expressing cells cultured without $(-)$ or with (+) Dox for 5 days to simultaneously induce shRNAs for $\beta$-catenin were assessed by western blotting with the indicated antibodies. b A representative image of Dox-treated ( + Dox) or untreated

against Dox-treated CRC cells can be explained by inhibition of a NHERF1-mediated survival response restricted to cells that silence $\beta$-catenin (Fig. 5). Moreover, RS5517 used as single agent did not substantially affect the survival, proliferation rate and clonogenic potential of $\operatorname{sh} \beta$-Cat transfected CRC cells (Fig. 7b, c). On the contrary, the combined use of $10 \mu \mathrm{M}$ RS5517 and Dox increased the proportion of apoptotic cells in the sub- $\mathrm{G}_{1}$ peak of the cell cycle compared with single-Dox exposure (86.6 vs 5.4\%) (Fig. 7c), by also impairing the clonogenicity of $\beta$-catenindepleted cells (Fig. 7d). Interestingly, RS5517 alone did not confer any proliferative advantage to CRC cells compared with shRNA-based NHERF1 knockdown (Supplementary Figure S2), while promoting the outgrowth of more cohesive cell colonies in soft agar (Fig. 7d).

Confocal immunofluorescence and cell fractionation analysis revealed that RS5517 markedly prevented the nuclear import of NHERF1 in CRC cells cultured in the absence or presence of Dox restoring its physiological membranous localization (Fig. 8a, b). Moreover, RS5517 did not change NHERF1 levels whilst it had stabilizing effects on the overall $\beta$-catenin protein content regardless of
shCTR or shNHERF1 expressing Ls174Tsh $\beta$-Cat or DLD1 $\operatorname{sh} \beta$-Cat cells from one of the six fields captured from each well by using a camera attached to an inverted Olympus IX51 microscope is shown. c Ls174Tsh $\beta$-Cat or DLD1sh $\beta$-Cat cells expressing a scramble control shCTR or specific shRNAs for NHERF1 (shNHERF1) were cultured without (-) or with (+) Dox for 5 days and then labeled by Annexin V/PI (propidium iodide) staining for apoptosis evaluation by flow cytometry. Values represent the mean \pm SD of three independent experiments. d Caspase- 3 activity was also measured and data reported as fold induction over vehicle-treated control samples

Dox treatment (Fig. 8b, c). To further exploit this issue, DLD1sh $\beta$-Cat cells were prior exposed to RS5517 and/or Dox for 3 days, then labeled with $\left[{ }^{35} \mathrm{~S}\right]$-methionine and chased with complete non-radioactive medium for additional 4 or $8 \mathrm{~h}$ to analyze metabolic stability of $\beta$-catenin by pull-down assays (Supplementary Figure S3). RS5517 delayed the protein degradation rate of $\beta$-catenin, as judged by densitometric analysis (expressing the intensity of the labeled $\beta$-catenin bands as a percentage of the value at time 0 ) indicating that the estimated half-life of $\beta$-catenin was longer than $8 \mathrm{~h}$ in RS5517-treated samples over DMSO control samples (-). The occurrence of apoptotic cell death in Ls174sh $\beta$-Cat cells exposed to Dox and RS5517 (Fig. 7) was further confirmed by the cleavage of PARP and reduced phospho-ERK1/2, Beclin-1 (BECN1) and the Rabeffector RILP protein levels compared to cells exposed to single-Dox treatment (i.e., only $\beta$-catenin silenced). Intriguingly, the RS5517-mediated targeting of NHERF1 did not affect the overall Rab7 expression neither at baseline or during $\beta$-catenin knockdown (Dox setting), in contrast to what herein reported for shRNA-mediated NHERF1 knockdown (Figs. 8c and 5a). 
A<smiles>O=C(Nc1ccc(CO)cc1)c1[nH]c2ccc(Cl)cc2c1Cc1ccccc1</smiles>

RS5517

B

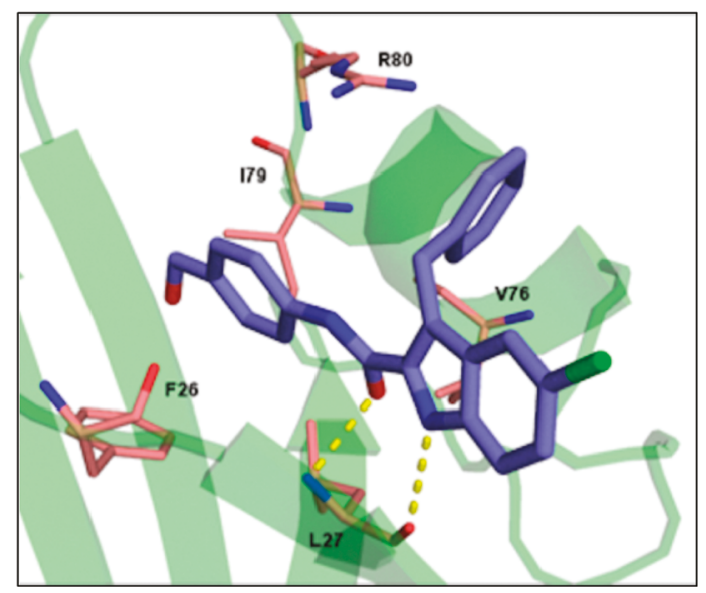

C

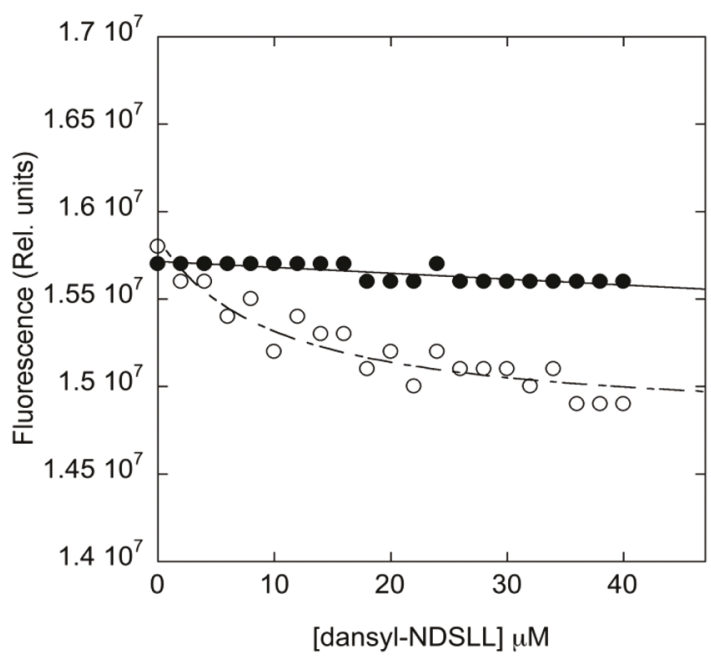

Fig. 6 RS5517 is a new PDZ1-domain antagonist of NHERF1. a The chemical structure of RS5517 derivative. b Proposed binding mode for derivative RS5517 (purple) to the NHERF1 PDZ1 domain that is depicted as green cartoon. Residues involved in interactions were reported as pink stick. H-bonds were shown as yellow dot lines. c Binding of PDZ1 NHERF1 Y38W to the ligand Dansyl-NDSLL in the presence (filled circles) and in the absence (open circles) of $5 \mathrm{mM}$ RS5517. Fluorescence data were recorded in the presence of $50 \mathrm{mM}$ Na phosphate, pH 7.2, $300 \mathrm{mM} \mathrm{NaCl}, 5 \mathrm{mM}$ DTT, 20\% DMSO, at $25^{\circ} \mathrm{C}$. Lines are the best fir to a hyperbolic binding transition. It is evident that binding between PDZ1 NHERF1 Y38W to the ligand Dansyl-NDSLL is abolished in the presence of RS5517
We finally tried to recapitulate our previous findings by the use of RS5517 and small-molecule inhibitors of $\beta$ catenin (Fig. 9). We show here that RS5517 synergized with $\beta$-catenin inhibitors FH535 and pyrvinium pamoate in triggering massive apoptosis of Ls174T and DLD1 colon cancer cells (Fig. 9a, b), thereby preventing persistent ERK1/2 phospho-activation mediated by single- $\beta$-catenin targeting (Fig. 9c).

\section{Discussion}

The PDZ-scaffold protein NHERF1 is over-expressed in breast and colon carcinomas [12-14], associated significantly with aggressive histological grade and poor prognosis [27-31]. By physically tethering several cancerrelated proteins, such as $\beta$-catenin [8], the tyrosine-kinase receptors PDGFR (platelet-derived growth factor receptor) [32] and EGFR (epidermal growth factor receptor) [33], some Wnt-ligand engaged receptors of the Frizzled (FZD) family [34], the tumor suppressor phosphatases PTEN (phosphatase and tensin homolog) [35] or PHLPP (PH leucine-rich repeat protein phosphatase) [36], NHERF1 engages in various functional complexes promoting specific phenotypic outcomes in cancer progression and metastatic organotropism [13, 27, 31]. However, NHERF1 is early lost and weakly re-expressed during the adenoma-toadenocarcinoma transition [8, 12, 27, 35], thus playing potential antinomic roles as tumor suppressor, when it maintains a proper membrane localization, or tumor promoter when its expression is lost or mislocalized in the cytoplasm and nucleus [7,9].

Loss of heterozygosity at the NHERF1 gene locus (17q25.1) or somatic intragenic missense mutations occur in the majority of human ovarian and breast cancers but not other diseases examined to date [37]. The promoter of NHERF1 gene contains estrogen-responsive elements [38], and NHERF1 expression was correlated with increasing ER (estrogen receptor) levels in $>90 \%$ of ER-positive breast carcinomas, while it is absent in ER-negative tumors associated with early recurrence and poor survival [39].

Regarding CRC, a recent study stated the tumor suppressor activity of NHERF1 [7, 8]. NHERF1 depletion exacerbated the transformed phenotype in vitro and in vivo, thereby increasing nuclear $\beta$-catenin signaling [8]. The present study extends these findings showing that mRNA transcript and protein levels of NHERF1 expression are negatively regulated by oncogenic $\beta$-catenin signaling in CRC cell lines harboring different $\mathrm{Wnt} / \beta$-catenin pathway mutations. Intriguingly, ChIP assays demonstrated that nuclear activated $\beta$-catenin can regulate NHERF1 via TCF4 directly, while the interaction between TCF1 and the nherf1 promoter increases upon $\beta$-catenin knockdown. These 

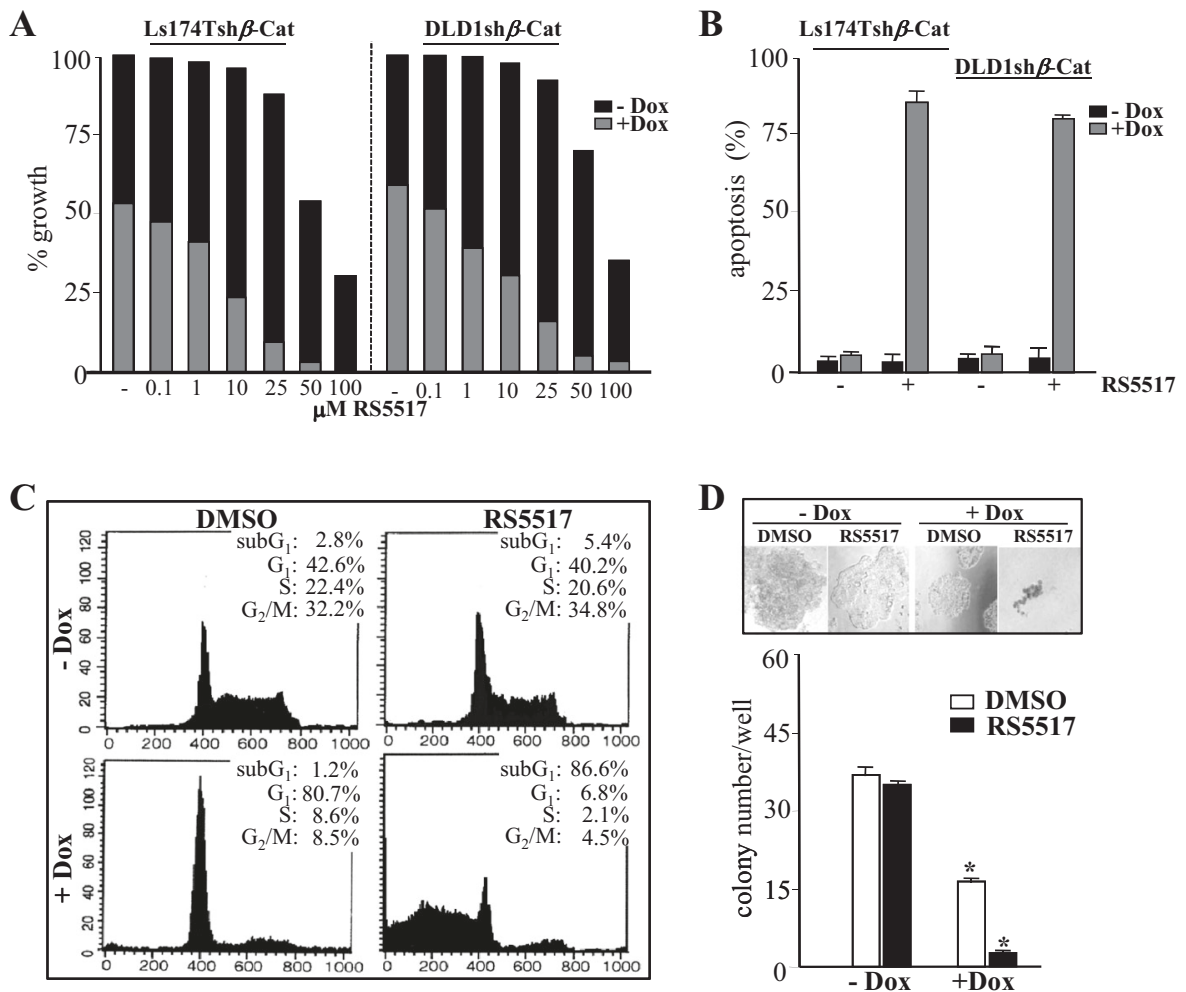

Fig. 7 RS5517 synergizes with shRNA-mediated silencing of $\beta$-catenin in promoting CRC cell death. a Proliferation assays of Ls174Tsh $\beta$ Cat or DLD1sh $\beta$-Cat cells exposed to increasing concentrations of RS5517 (range $0.1-100 \mu \mathrm{M}$ ) or vehicle alone $(-)$ in the absence or concomitant presence of Dox (-Dox/+Dox) for 5 days. Data were expressed as \% of growth inhibition. b Ls174Tsh $\beta$-Cat or DLD1sh $\beta$ Cat cells were treated with $10 \mu \mathrm{M}$ RS5517 in the absence or presence of Dox (-Dox/+Dox) for 5 days and then labelled by Annexin V-PE for apoptosis evaluation by flow cytometry. Values represent the mean $\pm \mathrm{SD}$ of three independent experiments. c Ls174Tsh $\beta$-Cat or DLD1sh $\beta$-Cat cells were treated with $10 \mu \mathrm{M}$ RS5517 (+) or DMSO as vehicle control (-) in the absence or concomitant presence of Dox

findings provide novel insight into the $\beta$-catenin/TCFdependent mechanisms of CRC carcinogenesis, suggesting that the relative amounts of $\beta$-catenin and those of different TCFs may ultimately dictate or relieve a default repression of nherfl gene, in keeping with the notion that TCFs function as powerful transcriptional activators or repressors [40]. NHERF1 expression is known to be negatively regulated by histone deacetylases [41], and was correlated with increasing levels of HIF1 $\alpha$ (hypoxia-inducible factor $1 \alpha$ ) $[27,31]$ that competes with TCF4 for direct binding to $\beta$ catenin under hypoxia [42]. Thus, it seems conceivable that either epigenetic changes and/or microenvironment cues may further integrate different molecular factors, within or outside the central $\mathrm{Wnt} / \beta$-catenin cascade, to modulate NHERF1 expression, as well as the phenotypic heterogeneity observed in primary human CRC $[8,11]$.

To our knowledge, this is the first report disclosing NHERF1 as a major survival driver in settings of $\beta$-catenin-
(-Dox/+Dox) for 5 days and then analyzed by propidium iodidestaining and flow cytometric analysis for assaying cell cycle distribution, as described in Methods section. A representative dot plot of three replicate experiments shows the percentages of cells into different phases of the cell cycle for each indicated treatment. $\mathbf{d}$ Number of Ls174Tsh $\beta$-Cat or DLD1sh $\beta$-Cat colonies formed in soft agar containing DMSO or $10 \mu \mathrm{M}$ RS5517 after 14 days. The values are presented as mean $\pm \mathrm{SD}$ of three independent experiments $(* P<0.05)$. A representative cell colony image was captured for the indicated treatment condition by using a camera attached to an inverted Olympus IX51 microscope

depleted CRC cells which adopt a cytostatic viable phenotype and a unique proteomic signature centred around autophagy and energy metabolism processes (i.e., ribosome biogenesis, spliceosome and RNA transport, oxidative stress and fatty acid degradation). Accordingly, recent evidence earmark NHERF1 as an autophagy regulator in breast cancers via its influence on the ubiquitin-dependent degradation of BECN1, a critical component of the autophagic core lipid kinase complex [43]. Moreover, NHERF1 was recently implicated in the oxidative stress response regulation in liver cancer cells via the recruitment of the MAPKactivated protein kinase 2 (MK2) that belongs to the stressinduced p38 MAPK pathway [44].

In our hands, genetic or pharmacological targeting of NHERF1 was sufficient to prime an 'autophagy-to-apoptosis switch' that strikingly impacted the fate of CRC cells during $\beta$-catenin knockdown. These data were remarkably consistent across two human CRC cell lines harboring 
Fig. 8 RS5517 prevents nuclear import of NHERF1 and $\operatorname{sh} \beta$ catenin-mediated accumulation of phospho-ERK1/2 and RILP in CRC cells. a DLD1sh $\beta$-Cat cells treated with $10 \mu \mathrm{M}$ RS5517 or DMSO in the absence or concomitant presence of Dox (-Dox/+Dox) for 5 days were stained using an anti-NHERF1 rabbit polyclonal primary antibody followed by an IgGFITC secondary antibody and DAPI staining for each indicated treatment. Each confocal image is representative of three independent

immunofluorescence experiments (Magnification, $\times 60)$. b Ls174Tsh $\beta$-Cat cells were treated with $10 \mu \mathrm{M}$ RS5517 or DMSO in the absence or concomitant presence of $2 \mu \mathrm{g} / \mathrm{mL}$ of Dox (-Dox/ + Dox) for 5 days and then fractionated to obtain purified extracts from either membrane, cytosol, and nucleus of cells, as described in Methods section. Equal amounts of each cell extract $(100 \mu \mathrm{g})$ were separated by SDS-PAGE and probed with the indicated antibodies. c Ls174Tsh $\beta$-Cat cells were exposed to $10 \mu \mathrm{M}$ RS5517 in the absence or concomitant presence of $2 \mu \mathrm{g} / \mathrm{mL}$ of Dox (-Dox/ + Dox) for 5 days and total lysates were then analyzed by western blotting with the indicated antibodies
A
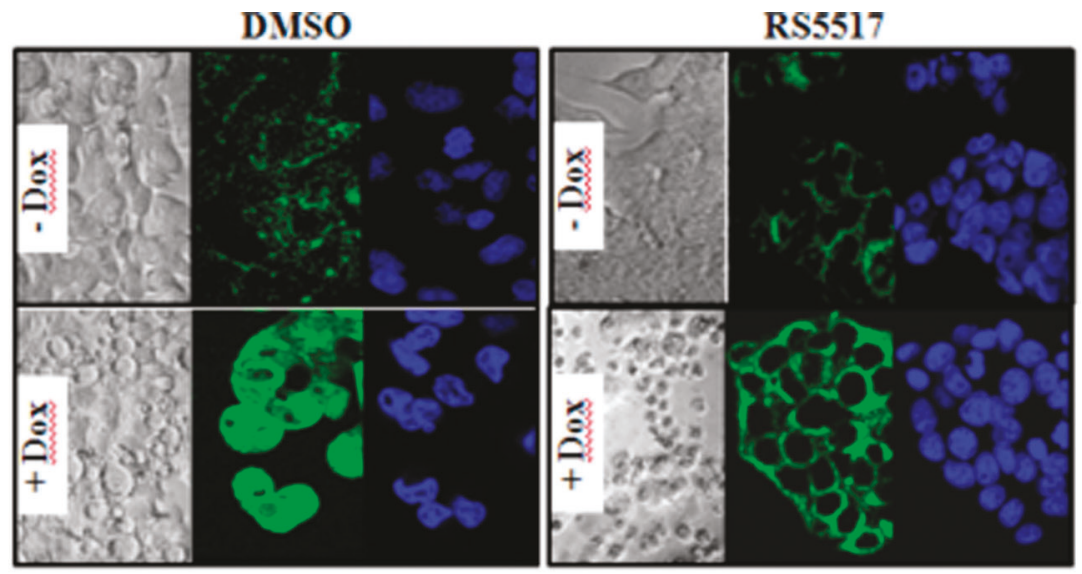

B

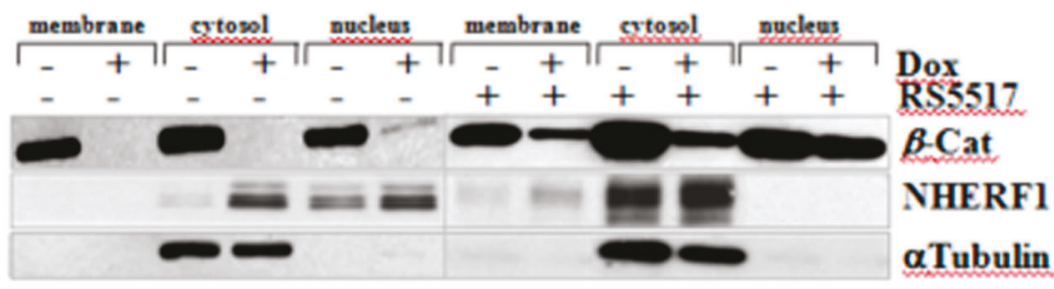

C

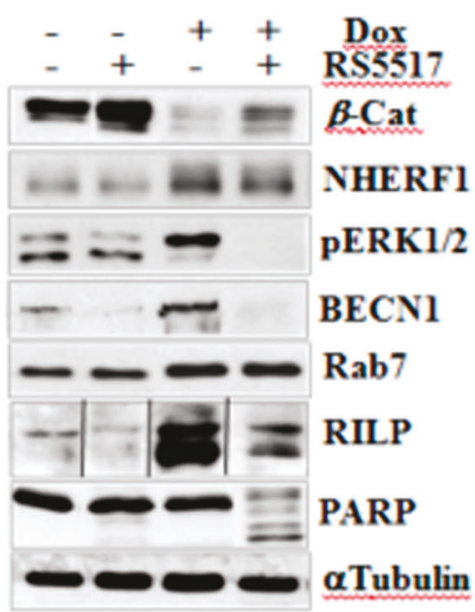

different $\mathrm{Wnt} / \beta$-catenin pathway mutations in $A P C / K R A S$ or $\beta$-catenin/KRAS genes, thus excluding any clonal effects. Mechanistically, combined targeting of NHERF1 and $\beta$ catenin triggered the activation of Caspase- 3 and the cleavage of PARP also abrogating the hyper-activation of ERK1/2, the accumulation of autophagy-related proteins like Beclin-1 (BECN1), Rab7 or its effector RILP elicited by single $\beta$-catenin knockdown. These molecular changes may relatively explain why a double $\beta$-catenin/NHERF1inhibitory strategy may be a fruitful mechanism-based strategy to augment apoptotic death of CRC cells refractory to $\mathrm{Wnt} / \beta$-catenin-targeted therapeutics $[3,5,6]$.
However, as physiological or pathological roles of NHERF1 strictly depend on its subcellular localization, targeted approaches aiming at modulating NHERF1 activity, rather than its overall expression, would be preferred to preserve the normal functions of this versatile protein. By far, particular attention has been paid to the NHERF1/ PDZ1-domain that governs its membrane recruitment/displacement through a transient phosphorylation switch [7, 21-23]. By using a rational virtual screening, we herein validated RS5517 as a novel NHERF1/PDZ1 ligand that abrogates its nuclear entry exhibiting a remarkable cytotoxicity on $\beta$-catenin-depleted CRC cells which highly reexpress NHERF1. 
A

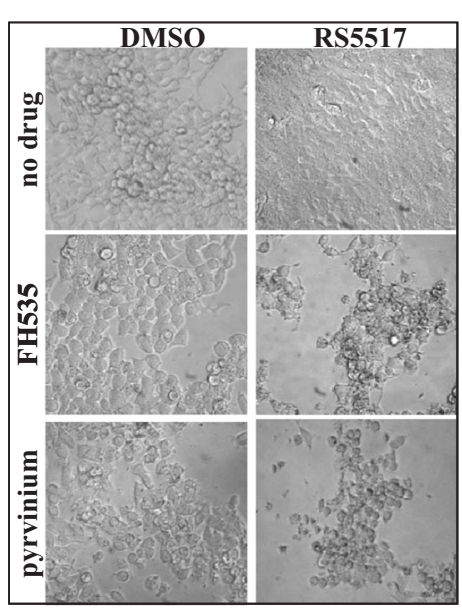

B

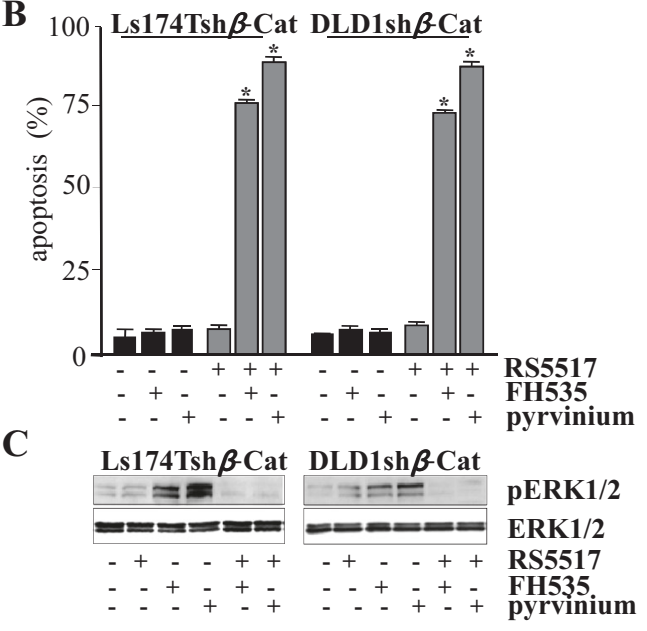

Fig. 9 RS5517 induces CRC cell death when combined to pharmacological inhibitors of $\beta$-catenin. a Ls174Tsh $\beta$-Cat cells were treated with $10 \mu \mathrm{M}$ RS5517 as single agent or in combination with FH535 (1 $\mu \mathrm{M})$ or pyrvinium pamoate $(150 \mathrm{nM})$ for 4 days and a representative image of one of the six fields captured from each well by using a camera attached to an inverted Olympus IX51 microscope is shown. b Ls174Tsh $\beta$-Cat or DLD1sh $\beta$-Cat cells treated with $10 \mu \mathrm{M}$ RS5517 alone or in combination with FH535 $(1 \mu \mathrm{M})$ or Pyrvinium pamoate

Although, further studies will exploit the safety profile of RS5517 in vivo, understanding that $\beta$-catenin signaling negatively regulates NHERF1 in CRC tumorigenesis will trigger the refinement of Wnt-targeted approaches to overcome the therapeutic resistance occurring at early disease stages.

\section{Materials and methods}

\section{Cells cultures and reagents}

Colorectal cancer (CRC) cell lines Ls174T and DLD-1 were purchased from the American Type Culture Collection (Manassas, VA, USA) and routinely assessed to check their identity [45]. Cells were stably transfected with Doxycycline hyclate (Dox)-inducible short hairpin RNA (shRNA) for $\beta$-catenin (Ls174Tsh $\beta$-Cat and DLD1sh $\beta$-Cat) or a scramble control shRNA (shCtr), as previously described $[3,45]$. To obtain NHERF1 downregulation, Ls174Tsh $\beta$ Cat and DLD1sh $\beta$-Cat were transfected with $250 \mathrm{nM}$ of NHERF1 shRNA (shNHERF1) or a scramble control shRNA (shCtr) (sc-156113) (Santa Cruz Biotechnology, CA, USA), according to the manufacturer's instructions.

FH535 (Calbiochem, San Diego, CA) and pyrvinium pamoate (Sigma-Aldrich) were resuspended in dimethylsulfoxide (DMSO, Sigma-Aldrich).
$(150 \mathrm{nM})$ for 4 days were then labelled by Annexin V/propidium iodide staining for apoptosis evaluation by flow cytometry. Values represent the mean $\pm \mathrm{SD}$ of three independent experiments $\left({ }^{*} P<\right.$ $0.003)$. c Total lysates from Ls174Tsh $\beta$-Cat or DLD1sh $\beta$-Cat cells treated with $10 \mu \mathrm{M}$ RS5517 alone or in combination with FH535 (1 $\mu \mathrm{M})$ or Pyrvinium pamoate $(150 \mathrm{nM})$ for 4 days were analyzed by western blotting with the indicated antibodies

\section{RT-PCR}

Total RNA of Ls174Tsh $\beta$-Cat and DLD1sh $\beta$-Cat cells was isolated using Trizol reagent (Invitrogen, Carlsbad, CA). The Nherf1 mRNA levels were determined using an RTPCR kit (New England Biolabs, Beverly, MA) and the following primers: forward 5'-CCCAGTGGCTATGGCTTCAA- $3^{\prime}$ and reverse 5'-GAAGTCTAGGATGGGGTCGG- $3^{\prime}$. The primers for $\beta$-actin were: forward $5^{\prime}$-CCACGGCTGCTTCCAGCTCC-3' and reverse 5'-GGAGGGCCGACTCGTCAT-3'. The relative Nherf1 mRNA abundance versus $\beta$-actin mRNA was quantified by Image $\mathbf{J}$ analysis.

\section{Chromatin immunoprecipitation (ChIP) assay}

A CHIP-KIP, including an anti-TCF4 antibody, a mouse IgG control and Gapdh promoter primers was from Millipore (\#17-10109). An anti-TCF1 antibody (clone 7H3) was also from Millipore. TCF-associated DNA immunoprecipitates were verified by qPCR using SYBR Green Mix (TaKaRa) and Nherfl promoter primers as follows: Nherf1 5'-CCTCCGTCTTAATTCTCGAG-3' (forward) and 5'-CCTTCACCTTCACAAACAAT-3' (reverse). Data are reported as percent input of each IP sample relative to input chromatin for each amplicon and ChIP sample. 


\section{Immunofluorescence staining}

Cells were assayed using an anti-NHERF1 (1:500; ThermoFisher, Rockford, IL) or $\beta$-catenin primary antibody (1:500; BD Transduction Laboratories, Lexington, KY) followed by Alexa Fluor 488-conjugated goat anti-rabbit IgG-FITC or a goat anti-rabbit IgG-TRITC (1:1000; Molecular Probes, Inc., Eugene, OR) secondary antibodies, and then analyzed using a confocal laser scanning microscope (LSM 710, Zeiss, Germany), equipped with a 60 oilimmersion objective and a spatial resolution of $200 \mathrm{~nm}$ in $x-y$ and $100 \mathrm{~nm}$ in $z$.

\section{Staining of monodansylcadaverine (MDC)-labeled vacuoles}

Cells were stained with $0.05 \mathrm{mM}$ MDC in PBS at $37^{\circ} \mathrm{C}$ for $10 \mathrm{~min}$, washed and assayed by fluorescence microscope (Nikon Eclipse TE300, Japan). Images were captured using Image Pro-plus software.

\section{Cell proliferation and apoptosis assays}

Cells $\left(10^{5}-50^{5}\right.$ cells/well $)$ were treated with serial dilutions of RS5517 or DMSO in the absence (-Dox) or presence (+Dox) of Dox in a volume of $200 \mu$ l. Cell growth was quantified by MTT (3-[4,5-dimethylthiazol-2-yl]-2,5diphenyl Tetrazolium bromide) (Sigma-Aldrich) according to manufacturer's recommendations. For apoptosis assays, the cells were stained with Annexin V-PE (BD-PharMingen, San Diego, CA) or Caspase-Glo assay kit (Promega) and analyzed by flow cytometry.

\section{Luciferase reporter assays, flow cytometry, and soft agar clonogenic analysis}

Cells were analyzed as previously described [45].

\section{Subcellular fractionation assays}

Cells were collected in the subcellular fractionation buffer (SF buffer): $250 \mathrm{mM}$ sucrose, $20 \mathrm{mM}$ HEPES (pH 7.4), $10 \mathrm{mM} \mathrm{KCl}, 1.5 \mathrm{mM} \mathrm{MgCl} 2,1 \mathrm{mM}$ EDTA and EGTA, to which $1 \mathrm{mM}$ DTT and protease/phosphatase inhibitors (1 mM PMSF; $5 \mathrm{mM} \mathrm{NaF}$ and $1 \mathrm{mM} \mathrm{Na} \mathrm{VO}_{4}$ ) were added at time of use. Lysates were then put on a tube roller (30-50 r.p.m.) at $4{ }^{\circ} \mathrm{C}$ for $30 \mathrm{~min}$ and centrifuged at $720 \times g$ at $4{ }^{\circ} \mathrm{C}$ for $5 \mathrm{~min}$. Pellet was washed with $500 \mu \mathrm{l}$ of SF buffer, centrifuged at $720 \times g$ at $4{ }^{\circ} \mathrm{C}$ for $10 \mathrm{~min}$, and dissolved for $15 \mathrm{~min}$ in nuclear lysis buffer (NL buffer): $50 \mathrm{mM}$ Tris- $\mathrm{HCl}$ (pH 8), $150 \mathrm{Mm} \mathrm{NaCl}, 1 \%$ NP-40, $0.5 \%$ sodium deoxycholate, $0.1 \%$ SDS, to which $10 \%$ glycerol and protease/phosphatase inhibitors were added at time of use. To obtain cytosolic fraction, the supernatant was centrifuged at $10,000 \times g$ at $4{ }^{\circ} \mathrm{C}$ for $10 \mathrm{~min}$ and ultracentrifuged at $100,000 \times g$ at $4{ }^{\circ} \mathrm{C}$ for $1 \mathrm{~h}$. To obtain the membrane fraction, the ultracentrifuged pellet was washed with $\mathrm{SF}$ buffer and ultracentrifuged at $100,000 \times g$ at $4{ }^{\circ} \mathrm{C}$ for $1 \mathrm{~h}$. Last pellet was dissolved in NL buffer and sonicated on ice.

\section{Pulse-chase analysis, immunoprecipitation, and western blotting}

Cells were assayed as previously described [45]. Primary antibodies were as follows: total $\beta$-catenin was from $\mathrm{BD}$ Transduction Laboratories, total NHERF1 from ThermoFisher, total c-Myc, cyclin D1, p27, Rab7, RILP, V1G1, Cathepsin D, and $\alpha$-Tubulin were from Santa Cruz Biotechnology Inc. (Santa Cruz, CA), total and phosphorylated pERK1/2 (pThr202/Tyr204) MAPK, total AKT, LC3, Beclin-1 (BECN1), and PARP were from Millipore.

\section{Sample preparation and mass spectrometry evaluation}

Quantity of $20 \mu \mathrm{g}$ of whole-protein extracts prepared using Illustra TriplePrep kit (GE Healthcare) were diluted 10-fold in $8 \mathrm{M}$ urea in $0.1 \mathrm{M}$ Tris- $\mathrm{HCl}, \mathrm{pH} 8.5$, filtered into the Microcon Ultracel YM-30 devices (Millipore), and centrifuged at $14,000 \times g$ for $15 \mathrm{~min}$. Samples were then further diluted in $8 \mathrm{M}$ urea, centrifuged again, reduced in $10 \mathrm{mM}$ DTT for $30 \mathrm{~min}$, and then alkylated in $50 \mathrm{mM}$ IAM for $20 \mathrm{~min}$. After four washes ( 2 in $8 \mathrm{M}$ urea and 2 in $50 \mathrm{mM}$ $\mathrm{NH}_{4} \mathrm{HCO}_{3}$ ), trypsin solution was added in an enzyme-toprotein ratio of $1: 100 \mathrm{w} / \mathrm{w}$, and samples were maintained at $37^{\circ} \mathrm{C}$ for $16 \mathrm{~h}$. Peptides were centrifuged and acidified by trifluoroacetic acid, desalted-concentrated on C-18 ZipTip (Millipore), dried under vacuum and then resuspended in $20 \mu \mathrm{l}$ of $\mathrm{ACN} / \mathrm{H}_{2} \mathrm{O}$ (FA 0.1\%) (2:98, v/v). Separation was obtained using an EASY-nLC 1000 UPLC (Thermo Scientific) through $75 \mathrm{~mm} \times 2 \mathrm{~cm}$ pre-column with nanoViper fittings (Acclaim pepMap 100, C18, $2 \mu \mathrm{m}$, Thermo Scientific) and $50 \mathrm{~mm}$ ID $\times 150 \mathrm{~mm}$ analytical column with nanoViper fittings (Acclaim PepMap RSLC, C18, $2 \mu \mathrm{m}$, Thermo Scientific). Elution was carried out over $120 \mathrm{~min}$ by using a 2-h gradient of ACN. The Q-Exactive instrument (Thermo Scientific) was set up to a spray voltage of $1.6 \mathrm{kV}$ and the survey scans were taken at 70,000 FWHM (at m/z 400) resolving power in positive ion mode with a scan range from 300 to $1600 \mathrm{~m} / \mathrm{z}$.

\section{Database searching and bioinformatics analysis}

Q-Exactive spectra were processed using the MaxQuant proteomics software (version 1.5.3.8) and matched using the Andromeda algorithm [46]. Trypsin was used as enzyme 
with two missed cleavages allowed. N-terminal acetylation and methionine oxidation were variable modifications, while carbamidomethylation of cysteines was a fixed modification. An initial mass spectra accuracy of 6 p.p.m. was selected, and the MS/MS tolerance was 20 p.p.m. for the HCD data with a false discovery rate of $1 \%$ for peptides and proteins identification. The MaxLFQ algorithm was used for assessing relative, label-free quantification of the proteins [47].

\section{Chemical synthesis of the RS5517 derivative}

RS5517, namely 3-benzyl-5-chloro-N-(4-(hydroxymethyl) phenyl)-1H-indole-2-carboxamide, was synthesized by coupling reaction of 3-benzyl-5-chloro-1H-indole-2-carboxylic acid with protected (4-(hydroxymethyl)aniline in the presence of PyBOP reagent and triethylamine in DMF. The product was deprotected by reaction with tetrabutylammonium fluoride solution (1 M in anhydrous THF).

\section{Virtual screening studies}

The NHERF1 PDZ1 domain was retrieved from the Protein Data Bank, under the PDB accession code 21GQ4 and the substrates (DSLL and ETVM) were drawn by Maestro (Schrödinger Release 2016-4: Maestro, Schrödinger, LLC, New York, NY, 2016) and analysed by molecular dynamics with Amber 12 [48]. The minimized structure was solvated in a periodic octahedron simulation box using TIP3P water molecules, providing a minimum of $10 \AA$ of water between the protein surface and any periodic box edge. Following minimization, the entire system was heated to $298 \mathrm{~K}$ $(20 \mathrm{ps})$, and the simulation was conducted at $298 \mathrm{~K}$ with constant pressure, periodic boundary condition and shake bond length condition $(\mathrm{ntc}=2)$. Trajectories analysis were carried out by the cpptraj modules [25]. This led to 5 structures for each complex which were used to draw a consensus pharmacophore model by Phase [26]. An in-house library of about 6000 compounds were docked into the binding site of each structures by Plants [49]. Structures fitting the pharmacophore queries were selected for biological evaluation. Picture was depicted by Pymol (PyMOL version 1.2r1. DeLanoScientificLLC:SanCarlos, CA).

\section{In vitro binding studies}

A NHERF1 PDZ1 subcloned in pETG41 plasmid was kindly obtained from Dr. Nicolas Wolff (Pasteur Institute, Paris, France). A site-directed mutagenesis by Quickchange Lighting mutagenesis kit was confirmed by DNA sequencing. A dansylated peptide relative to the $\mathrm{C}$-terminal portion of the $\beta 2$-adrenergic receptor, $D$-NDSLL, was from JPT Peptide Technologies (Berlin, Germany) and purified using HPLC. Equilibrium binding experiments were carried out in

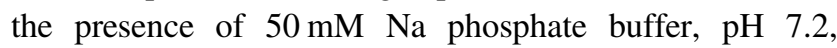
$300 \mathrm{mM} \mathrm{NaCl}$ at $25^{\circ} \mathrm{C}$ by monitoring fluorescence upon exciting the sample at $280 \mathrm{~nm}$ and measuring emission on a Fluoromax single-photon spectrofluorometer (Jobin-Yvon, NJ, USA) [50].

\section{Statistical analysis}

Data are reported as the mean \pm SEM. Significance levels were determined with the Student's $t$-test. Proteomic statistical analysis was perfomed with the Perseus software (version 1.5.2.4). Multiple-samples tests were performed using ANOVA test by using a false discovery rate threshold of 0.05 and preserving grouping in randomization. Hierarchical clustering of proteins was performed in Perseus on logarithmized intensities after $z$-score normalization of the data, using Euclidean distances. Gene Ontology (GO) and Kyoto Encyclopedia of Genes and Genomes (KEGG) analysis of our protein dataset was performed by STRING version 10 (http://string-db.org) (Nucleic Acids Res 2015; 43(Database issue):D447-52. doi: 10.1093/nar/ gku1003).

Acknowledgements We thank Dr. Hans Clevers (Hubrecht Laboratory, Utrecht, The Netherlands) for providing the $\mathrm{pcDNA}_{6} \mathrm{TR}$ and pTER vectors. We gratefully acknowledge funding from Italian Association for Cancer Research (AIRC)-Investigator Grant (IG) 2014 No. 14236 (AMLC). This work was partially supported by Italian Grant PRIN 2015 (2015FCHJ8E) (RS), European Union's Horizon 2020 Research and Innovation program under the Marie Skłodowska-Curie grant agreement No. 675341 (SG), AIRC IG 2016 No. 19068 (CB) and Apulia Regione Cluster Project SISTEMA No. T7WGSJ3 (MM). MDL was recipient of a Veronesi Foundation fellowship. We warmly thank Dr. Antonio Danieli for his technical assistance.

\section{Compliance with ethical standards}

Conflict of interest The authors declare that they have no conflict of interest.

Open Access This article is licensed under a Creative Commons Attribution 4.0 International License, which permits use, sharing, adaptation, distribution and reproduction in any medium or format, as long as you give appropriate credit to the original author(s) and the source, provide a link to the Creative Commons license, and indicate if changes were made. The images or other third party material in this article are included in the article's Creative Commons license, unless indicated otherwise in a credit line to the material. If material is not included in the article's Creative Commons license and your intended use is not permitted by statutory regulation or exceeds the permitted use, you will need to obtain permission directly from the copyright holder. To view a copy of this license, visit http://creativecommons. org/licenses/by/4.0/. 


\section{References}

1. Frattini M, Balestra D, Suardi S, Oggionni M, Alberici P, Radice $\mathrm{P}$, et al. Different genetic features associated with colon and rectal carcinogenesis. Cancer Res. 2004;10:4015-21.

2. Janssen KP, Alberici P, Fsihi H, Gaspar C, Breukel C, Franken P, et al. APC and oncogenic KRAS are synergistic in enhancing Wnt signaling in intestinal tumor formation and progression. Gastroenterology. 2006;131:1096-109.

3. Mologni L, Brussolo S, Ceccon M, Gambacorti-Passerini C. Synergistic effects of combined Wnt/KRAS inhibition in colorectal cancer cells. PLoS ONE. 2012;7:e51449.

4. Song L, Li Y, He B, Gong Y. Development of small molecule targeting the Wnt signaling pathway in cancer stem cells for the treatment of colorectal cancer. Clin Colorectal Cancer. 2015;14:133-45.

5. van de Wetering M, Oving I, Muncan V, Pon Fong MT, Brantjes $H$, van Leenen $D$, et al. Specific inhibition of gene expression using a stably integrated, inducible small-interfering-RNA vector. EMBO Rep. 2003;4:609-15.

6. Verma UN, Surabhi RM, Schmaltieg A, Becerra C, Gaynor RB. Small interfering RNAs directed against beta-catenin inhibit the in vitro and in vivo growth of colon cancer cells. Clin Cancer Res. 2003;9:1291-1300.

7. Vaquero J, Nguyen Ho-Bouldoires TH, Claperon A, Fouassier L. Role of the PDZ-scaffold protein NHERF1/EBP50 in cancer biology: from signaling regulation to clinical relevance. Oncogene. 2017;36:3067-79.

8. Georgescu MM, Gagea M, Cote G. NHERF1/EBP50 suppresses Wnt- $\beta$-catenin pathway-driven intestinal neoplasia. Neoplasia. 2016;18:512-23.

9. Georgescu MM, Morales FC, Molina JR, Hayashi Y. Roles of NHERF1/EBP50 in cancer. Curr Mol Med. 2008;8:459-68.

10. Hayashi Y, Molina JR, Hamilton SR, Georgescu MM. NHERF1/ EBP50 is a new marker in colorectal cancer. Neoplasia. 2010;22:1013-22.

11. Georgescu MM, Cote G, Agarwal NK, White CL. NHERF1/ EBP50 controls morphogenesis of 3D colonic glands by stabilizing PTEN and ezrin-radixin-moesin proteins at the apical membrane. Neoplasia. 2014;16:365-74.

12. Mangia A, Saponaro C, Malfettone A, Bisceglie D, Bellizzi A, Asselti M, et al. Involvement of nuclear NHERF1 in colorectal cancer progression. Oncol Rep. 2012;28:889-94.

13. Saponaro C, Malfettone A, Dell'Endice TS, Brunetti AE, Achimas-Cadariu P, Paradiso A, et al. The prognostic role of the $\mathrm{Na}+/ \mathrm{H}+$ exchanger regulatory factor 1 (NHERF1) protein in cancer. Cancer Biomark. 2014;14:177-84.

14. Yang M, Zhong WW, Srivastava N, Slavin A, Yang J, Hoey T, et al. G protein-coupled lysophosphatidic acid receptors stimulate proliferation of colon cancer cells through the beta-catenin pathway. Proc Natl Acad Sci USA. 2005;102:6027-32.

15. Ilyas M, Tomlinson IP, Rowan A, Pignatelli M, Bodmer WF. Beta-catenin mutations in cell lines established from human colorectal cancers. Proc Natl Acad Sci USA. 1997;94:10330-34.

16. Gayet J, Zhou XP, Duval A, Rolland S, Hoang JM, Cottu P, et al. Extensive characterization of genetic alterations in a series of human colorectal cancer cell lines. Oncogene. 2001;20:5025-32.

17. Handeli S, Simon JA. A small-molecule inhibitor of Tcf/betacatenin signaling down-regualtes PPARgamma and PPARdelta activities. Mol Cancer Ther. 2008;7:521-29.

18. Thorne CA, Hanson AJ, Schneider J, Tahinci E, Orton D, Cselenyi CS. Small molecule inhibition of Wnt signaling through activation of casein kinase 1alpha. Nat Chem Biol. 2010;6:829-36.
19. Cantalupo G, Alifano P, Roberti V, Bruni CB, Bucci C. Rabinteracting lysosomal protein (RILP): the Rab7 effector required for transport to lysosomes. EMBO J. 2001;20:683-93.

20. De Luca M, Cogli L, Progida C, Nisi V, Pascolutti R, Sigismund $\mathrm{S}$, et al. RILP regulates vacuolar ATPase through interaction with the V1G1 subunit. J Cell Sci. 2014;127:2697-708.

21. Mayasundari A, Ferreira AM, He L, Mahindroo M, Bashford D, Fujii N. Rational design of the first small-molecule antagonists of NHERF1/EBP50 PDZ domains. Bioorg Med Chem Lett. 2008;18:942-45.

22. Du G, Gu Y, Hao C, Yuang Z, He J, Jiang WG, et al. The cellular distribution of $\mathrm{Na}+/ \mathrm{H}+$ exchanger regulatory factor 1 is determined by the PDZ-I domain and regulates the malignant progression of breast cancer. Oncotarget. 2016;7:29440-53.

23. Fitzpatrick JM, Pellegrini M, Cushing PR, Mierke DF. Small molecule inhibition of $\mathrm{Na}(+) / \mathrm{H}(+)$ exchange regulatory factor 1 and parathyroid hormone 1 receptor interaction. Biochemistry. 2014;53:5916-22.

24. Mamonova T, Kunikova M, Friedman PA. Structural basis for NHERF1 PDZ domain binding. Biochemistry. 2012;51:3110-20.

25. Roe DR, Cheatham TE. PTRAJ and CPPTRAJ: Software for processing and analysis of molecular dynamics trajectory data. $\mathbf{J}$ Chem Theory Comput. 2013;9:3084-95.

26. Dixon SL, Smondyrev AM, Rao NS. PHASE: a novel approach to pharmacophore modeling and 3D database searching. Chem Biol Drug Des. 2006;67:370-72.

27. Cardone RA, Bellizzi A, Busco G, Weinman EJ, Dell'Aquila ME, Casavola V, et al. The NHERF1 PDZ2 domain regulates PKARhoA-p38-mediated NHE1 activation and invasion in breast tumor cells. Mol Biol Cell. 2007;18:1768-80.

28. Song GJ, Leslie KL, Barrick S, Mamonova T, Fitzpatrick JM, Drombosky KW, et al. Phosphorylation of ezrin-radixin-moesinbinding phosphoprotein 50 (EBP50) by Akt promotes stability and mitogenic function of S-phase kinase-associated protein-2 (Skp2). J Biol Chem. 2015;290:2879-87.

29. Bellizzi A, Mangia A, Malfettone A, Cardone RA, Simone G, Reshkin SJ, et al. $\mathrm{Na}+/ \mathrm{H}+$ exchanger regulatory factor 1 expression levels in blood and tissue predict breast tumour clinical behaviour. Histopathology. 2011;58:1086-95.

30. Karn T, Pusztai L, Holtrich U, Iwamoto T, Shiang CY, Schmidt $\mathrm{M}$, et al. Homogeneous datasets of triple negative breast cancers enable the identification of novel prognostic and predictive signatures. PLoS ONE. 2011;6:e28403.

31. Malfettone A, Silvestris N, Paradiso A, Mattioli E, Simone G, Mangia A. Overexpression of nuclear NHERF1 in advanced colorectal cancer: association with hypoxic microenvironment and tumor invasive phenotype. Exp Mol Pathol. 2012;92:296-303.

32. Maudsley S, Zamah AM, Rahman N, Blitzer JT, Luttrell LM, Lefkowitz RJ, et al. Platelet-derived growth factor receptor association with $\mathrm{Na}(+) / \mathrm{H}(+)$ exchanger regulatory factor potentiates receptor activity. Mol Cell Biol. 2000;20:8352-63.

33. Lazar CS, Cresson CM, Lauffenburger DA, Gill GN. The $\mathrm{Na}+/ \mathrm{H}$ + exchanger regulatory factor stabilizes epidermal growth factor receptors at the cell surface. Mol Biol Cell. 2004;15:5470-78.

34. Wheeler DS, Barrick SR, Grubisha MJ, Brufsky AM, Friedman PA, Romero G. Direct interaction between NHERF1 and Frizzled regulates $\beta$-catenin signaling. Oncogene. 2011;30:32-42.

35. Takahashi Y, Morales FC, Kreimann EL, Georgescu MM. PTEN tumor suppressor associates with NHERF proteins to attenuate PDGF receptor signaling. EMBO J. 2006;25:910-20.

36. Molina JR, Agarwal NK, Morales FC, Hayashi Y, Aldape KD, Cote $\mathrm{G}$, et al. PTEN, NHERF1 and PHLPP form a tumor suppressor network that is disabled in glioblastoma. Oncogene. 2012;31:1264-67. 
37. Pan Y, Wang L, Dai JL. Suppression of breast cancer cell growth by $\mathrm{Na}+/ \mathrm{H}+$ exchanger regulatory factor 1 (NHERF1). Breast Cancer Res. 2006;8:R63.

38. Ediger TR, Kraus WL, Weinman EJ, Katzenellenbogen BS. Estrogen receptor regulation of the $\mathrm{Na}+\mathrm{H}+$ exchange regulatory factor. Endocrinology. 1999;140:2976-82.

39. Stemmer-Rachamimov AO, Wiederhold T, Nielsen GP, James M, Pinney-Michalowski D, Roy JE, et al. NHE-RF, a merlininteracting protein, is primarily expressed in luminal epithelia, proliferative endometrium, and estrogen receptor-positive breast carcinomas. Am J Pathol. 2001;158:57-62.

40. Blauwkamp TA, Chang MV, Cadigan KM. Novel TCF-binding sites specify transcriptional repression by Wnt signalling. EMBO J. 2008;27:1436-46.

41. Schroeder TM, Nair AK, Staggs R, Lamblin AF, Westendorf JJ. Gene profile analysis of osteoblast genes differentially regulated by histone deacetylase inhibitors. BMC Genom. 2007;8:362.

42. Kaidi A, Williams AC, Paraskeva C. Interaction between betacatenin and HIF-1 promotes cellular adaptation to hypoxia. Nat Cell Biol. 2007;9:210-7.

43. Liu H, Ma Y, He HW, Wang JP, Jiang JD, Shao RG. SLC9A3R1 stimulates autophagy via BECN1 stabilization in breast cancer cells. Autophagy. 2015;11:2323-34.

44. Nguyen Ho-Bouldoires TH, Clapéron A, Mergey M, Wendum D, Desbois-Mouthon C, Tahraoui S, et al. Mitogen-activated protein kinase-activated protein kinase 2 mediates resistance to hydrogen peroxide-induced oxidative stress in human hepatobiliary cancer cells. Free Radic Biol Med. 2015;89:34-46.

45. Coluccia AM, Benati D, Dekhil H, De Filippo A, Lan C, Gambacorti Passerini C. SKI-606 decreases growth and motility of colorectal cancer cells by preventing pp60(c-Src)-dependent tyrosine phosphorylation of $\beta$-catenin and its nuclear signalling. Cancer Res. 2006;66:2279-86.

46. Cox J, Neuhauser N, Michalski A, Scheltema RA, Olsen JV, Mann M. Andromeda: a peptide search engine integrated into the MaxQuant environment. J Proteome Res. 2011;10:1794-805.

47. Cox J, Hein MY, Luber CA, Paron I, Nagaraj N, Mann M. Accurate proteome-wide label-free quantification by delayed normalization and maximal peptide ratio extraction, termed MaxLFQ. Mol Cell Proteom. 2014;13:2513-26.

48. Case DA, Darden TA, Cheatham TE, Simmerling CL, Wang J, Duke RE, et al.. AMBER 12. San Francisco: University of California; 2012.

49. Korb O, Stützle T, Exner TE. An ant colony optimization approach to flexible protein-ligand docking. Swarm Intell. 2007;1:115-34.

50. Ivarsson Y, Travaglini-Allocatelli C, Jemth P, Malatesta F, Brunori M, Gianni S. An on-pathway intermediate in the folding of a PDZ domain. J Biol Chem. 2007;282:8568-72. 